\title{
ОБ ОСНОВАХ И ПЕРСПЕКТИВАХ КОНЦЕПЦИИ «ЗЕЛЕНОГО» ПОТРЕБЛЕНИЯ СРЕДИ СТУДЕНТОВ КОЛЛЕДЖЕЙ
}

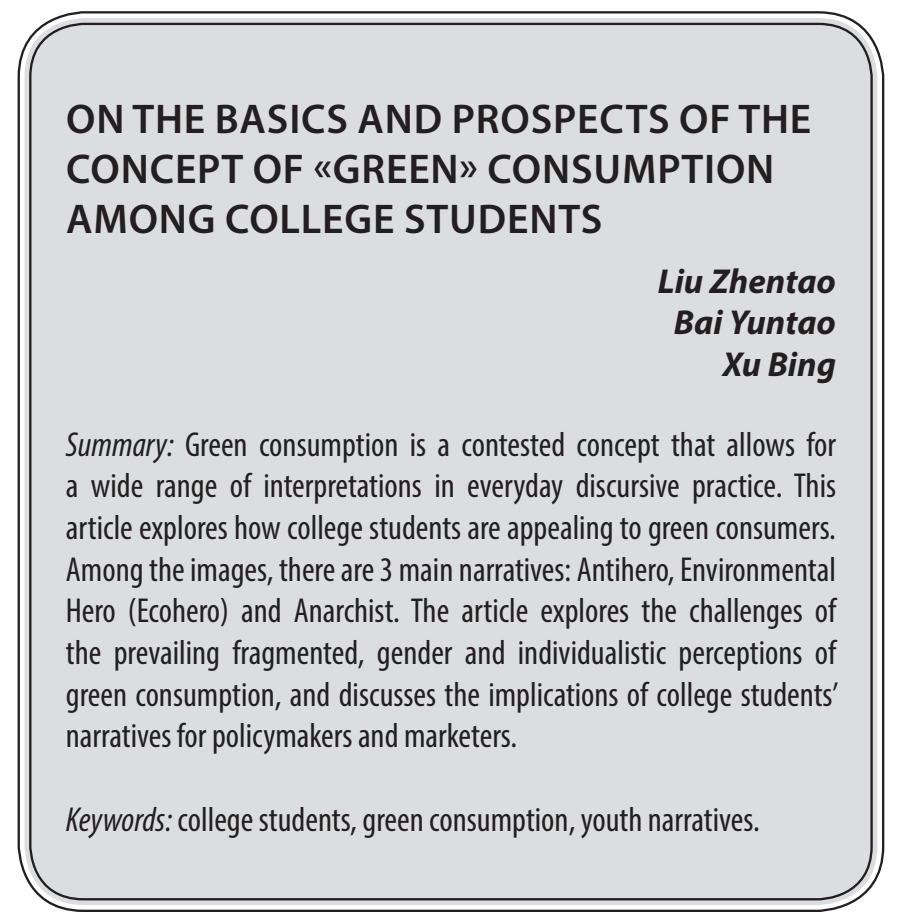

\section{Введение}

$\Pi$ роизводили различных категорий товаров могут внедрять новые технологии и оборудование для сокращения оказываемого отрицательного воздействия на состояние окружающей среды и экологии. Однако все прилагаемые усилий производителей будут сводиться к нулю, если сами потребители не разделяют ценностей «зеленого» потребления. Таким образом, ключевое значение для функционирования рынка имеет потребительский выбор. Сегодня отмечается тенденция, когда покупатели стремятся приобретать те товары и продукты, которые приносят минимальный вред окружающей среде, что в результате оказывает мотивирующее действие на производителей.

Согласно данным Европейской комиссии [1], молодые потребители, то есть студенты колледжей и прочих учебных заведений, имеют сегодня власть и ответственность. Данное политическое утверждение еще раз доказывает, что каждый потребитель, будучи суверенных экономическим агентом, может оказывать воздействие на практики и структуру той или иной потребительской культуры.

Сегодня «зеленое» потребление является актуальным феноменом потребительской культуры практически всех стран мира. В ходе исследований ученые пыта-

\begin{abstract}
Лю Чжэньтао
помощник н.с., Хэйхэский университет КНР 714913879@qq.com

Бай Юньтао

М.н.С., Хэйхэский университет КНР

Сюй Бин

помощник н.С., Хэйхэский университет КНР
\end{abstract}

Аннотация: «Зеленое потребление» - это оспариваемая концепция, допускающая широкий диапазон трактовок в повседневной дискурсивной практике. В данной статье исследуется, какими образами зеленых потребителей апеллируют студенты колледжей. (реди образов можно выделить 3 основных нарратива: Антигерой, Герой окружающей среды (Экогерой) и Анархист. В статье раскрываются проблемы преобладающих фрагментированных, гендерных и индивидуалистических представлений о зеленом потреблении, обсуждаются последствия нарративов студентов колледжей для политиков и специалистов по маркетингу.

Ключевые слова: студенты колледжей, «зеленое» потребление, нарративы молодежи.

лись выявить влияние на «зеленое» потребление таких факторов как личностные характеристики и гендер.

Исследователи из Канады в своей работе говорят о том, что учитывая влияние уровня экологичности продукции на спрос, строится двухэтапная замкнутая цепочка поставок, состоящая из одного производителя и одного розничного продавца. В рамках как децентрализованных, так и централизованных моделей принятия решений глубоко исследуются различия в системе цепочки поставок с точки зрения экономических выгод, защиты окружающей среды и социальных выгод, а также применяется договор о распределении доходов для реализации координации между производителем и розничным продавцом. Результаты исследования канадских ученых показали, что система цепочки поставок в централизованной модели принятия решений более эффективна, чем в децентрализованной модели принятия решений относительно экономических выгод, защиты окружающей среды и социальных льгот, а договор о распределении доходов имеет отличный потенциал для координирования цепочки поставок. Согласно двум моделям принятия решений были сделаны следующие выводы:

1. Уровень экологичности продукции, норма прибыли и прибыль узлового предприятия положительно коррелируют с осведомленностью потребителей об окружающей среде и отрицательно 
коррелируют с чувствительностью к цене, а также с параметром затрат зеленых инвестиций.

2. Цена положительно коррелирует с масштабным параметром сбора и обработки.

3. Норма возврата и прибыль узлового предприятия имеют отрицательную корреляцию, и уровень экологичности продукции не имеет значения [2].

Следующее исследование, реализованное исследователями из Испании, демонстрирует необходимость проанализировать переменные, которые формируют потребительский профиль «зеленого» потребителя. Ученые сосредоточились на психографических переменных и, в частности, на особенностях личности. После опроса случайной выборки из 573 человек была разработана теоретическая модель, которая включала в себя шкалу пяти факторов структуры и измерение отношения к окружающей среде, называемое «фактической приверженностью» для измерения личности и экологического поведения соответственно. Было реализовано несколько основных факторных анализов, чтобы проверить эти шкалы, а затем был реализован анализ структурных уравнений. Полученные данные подтверждают наши гипотезы, поскольку они показывают, что личность - это многогранное понятие, которое положительно связано с экологическим поведением. Компании-производители должны сосредоточиться на людях, для которых характерны такие черты характера, как экстраверсия, покладистость и добросовестность, чтобы убедить их требовать свою продукцию [3].

Большая доля современных исследований стремится объяснить систему отношений, которая наблюдается между намерениями, приоритетами, проэкологическими установками и нормами потребителей, разделяющий концепцию «зеленого» потребления $[4,5]$.

Исследователи уделяют особо внимание контекстуальным факторам, которые оказывают существенное воздействие на отношения между потребительским поведением и уровнем заботы о состоянии экологии, окружающей среды $[6,7,8,9]$.

Таким образом, забота об экологии и концепция «зеленого» потребления как современные культурные феномены являются актуальными предметами изучения и споров $[10,11]$.

Целью данной работы является определение основных нарративов, которые студенты колледжей используют для конструирования своей идентичности в качестве «зеленых» потребителей. Нарративы были интерпретированы в качестве культурных и языковых образов, которые иллюстрируют культурные ресурсы и дискурсы, а также дискурсивные практики. Одной их задач исследования было отображения и представление «зеленого» потребления через нарративы студентов колледжей, сформированные на основании культурных дискурсов.

Для выявления нарративов студентов колледжей китайского общества, относительно благополучного, с высоким уровнем образования, были проанализированы эссе учащихся в возрасте от 16 до 20 лет. Студентам предлагалось написать эссе в одном из двух направлений:

1. Потребительская автобиография.

2. Потребление, которое отличается дружественным отношением к состоянию окружающей среды.

В результате было получено 52 эссе по первой теме и 161 - по второй. Данное исследование было сконцентрировано на второй группе. Проведенный контент-анализ эссе позволил выделить главные темы, освещаемые обучающимися:

1. Ресайклинг.

2. Сокращение объемов потребления.

3. Увеличение доли экотоваров.

После первичного контент-анализа был выполнен анализ структуры нарративов: какими отличительными характеристиками они обладают, по каким сюжетным линиям выстраиваются, какие моральные дилеммы они затрагивают.

Сбор и анализ эссе было первым этапом исследования. После этого был проведен ряд дискуссий с фокус-группами из студентов колледжей с той же целью: выявление и определение нарративов «зеленого» потребления.

Таким образом, в ходе реализации исследования использовались следующие методы: литературный обзор, контент-анализ, сравнительный анализ, дедукция и индукция, структурно-функциональный метод, системный подход, формализация, проведение дискуссий с участием фокус-группы, сущностный анализ, обобщение.

Основными материалами стали литературные источники, эссе студентов колледжей и информация, полученная в ходе проведения дискуссий с фокус-группами.

Было выявлено, что нарративы «зеленого» потребления среди студентов колледжей сформированы на основании следующих культурных дискурсов:

1. Индивидуалистический моральный дискурс. Потребитель позиционируется как примерный гражданин, характеризующийся высокой степенью информированности, рациональными поведением (с точки зрения морали).

2. Дискурс духовно ориентированного «зеленого» потребления. Основной в данном случае выступает концепция «voluntary simplicity», то есть добро- 
вольной скромности и добровольного отказа от чрезмерного консьюризма.

3. Дискурс контркультурного «зеленого» потребления. В рамках данного дискурса потребитель позиционируется как фанатичный и асоциальны активист, основной задачей которого является защита окружающей среды иногда с применением радикальных форм. К примеру, для него распространённой практикой является культурный «экофеминизм» или глубинная экология.

Были выявлены следующие нарративы:

1. Антигерой. Приставка «анти» обусловлена отрицанием данной категории потребителей концепции «зеленого» потребления. Такой потребитель не придерживается норм и положений устойчивого развития и консьюризма. Свою позицию он обосновывает отсутствием возможности изменить современную культуру и весь мир в целом силами одного индивида.

2. Экогерой. Это потребитель, который полностью осознает важность «зеленых» практик для эффективного решения имеющихся экологических проблем. Данная категория предпочитает безопасные экопродукты традиционным товарам и продуктам.

3. Анархист. Такой потребитель выражает критическое отношение к консьюризму, при этом он соблюдает основные положения и основополагающие стандарты или принципы «зеленого» потребления.

Остановимся более подробно на каждом из перечисленных нарративов, их отличительных характеристиках.

\section{Антигерой}

В целом данный нарратив демонстрирует, что сегодняшние студенты колледжей знакомы с экологическими проблемами и имеют представление о вариантах их решения. Однако каждый отдельный индивид считает, что не в силах изменить текущее положение дел только в рамках собственных возможностей. Это ведет к тому, что каждый отдельный индивид решает не отказывать себе в удовольствии потребления.

Поколение сегодняшних студентов колледжей выросло в условиях выявленных и четко обозначенных экологических проблем. Общество, в котором они росли и воспитывались, подталкивало население увеличивать объем индивидуального потребления, навязывая широкий спектр материальных ценностей (не всегда оправданных и действительно нужных тому или иному индивиду). Параллельно с этим в обществе транслировались идеи необходимости принятия особых мер для нормализации экологической ситуации и улучшения те- кущего состояния окружающей среды. В результате, молодежь, относящаяся к категории «антигероев» знакома с концепцией «зеленого» потребления, ее нормами и основами, хотя сами они их не разделяют и не придерживаются. Главной целью антигероев является ведение максимально комфортной жизни, в какой-то мере «гедонистической», которая противоречит привычным идеалам «зеленого» потребления.

\section{Экогерой}

Это молодые потребители, которые полностью разделяют, поддерживают и внедряют в свою жизнь нормы и стандарты концепции «зеленого» консьюризма. Для них это не является радикальной мерой, это выбор, который осознанно совершается каждый день. Такие потребители росли и воспитывались в условиях, когда распространенной практикой являлись:

1. Сдача упаковок и бытовых отходов для дальнейшей переработки.

2. Потребление продукции, которая отвечает требованиям дружественного отношения к окружающей среде.

3. Разделение мусора и так далее.

Эти и другие меры были распространены в среде, где росли нынешние студенты колледжей, поэтому они привыкли к ней и внедрили полезные, с экологической точки зрения, привычки в свою модель поведения.

В большинстве случаев проявления приверженности «зеленому потреблению» выражается посредством обдуманных предпочтений потребителей, когда выбор отдается натуральным, органически чистым продуктам, 100\% экологичным. Вторым основным проявлением является управление домашними отходами, их переработка и/или сортировка.

\section{Анархист}

Данный потребитель является оппонентом для двух описанных выше нарративов. Он противится как «антизеленой» концепции и увеличенному индивидуальному консьюризму, так и концепции 2зеленого» консьюризма. Приверженцы данного вектора считают, что сегодня крайне трудно произвести стопроцентно экологичный продукт, а также крайне сложно проверить, насколько продукт в реальности соответствует заявленной экологичности.

Основными характеристиками потребителя данного нарратива является критическое отношение ко всем представленным продуктам и товаров, выбор основывается на рациональном сопоставлении состава, стоимости, получаемых преимуществ и прочих свойств; трезвая и субъективная оценка. 


\section{Закиючение}

Выполненное исследование позволяет сделать следующий вывод: индивидуалистичное понимание «зеленого» потребления в рамках фрагментированного изучения нарративов студентов колледжей позволяет более глубоко изучить ситуацию.

Общество должно модернизировать свои моралистические взгляды, в том числе менять позиционирование и отношение к таким востребованным молодежью товарам как модная одежда, гаджеты, фаст-фуд. В противном случае можно наблюдать реакцию защиты.

Вместо того, чтобы публиковать материалы о необходимости перевода тех или иных областей в русло «зеленого» потребления, более эффективно выделить и сконцентрировать усилия на ряде конкретных приоритетов и векторов внутри данной концепции.

Проведенное исследование демонстрирует необходимость студентов колледжей чувствовать значимость их действий. Это диктует необходимость вовлечения молодежи в поиск, разработку и реализацию мер, направленных на развитие «зеленого» консьюризма.

Для повышения эффективности «зеленого» дискурса и концепции в целом, необходимо признать важность социальной природы и потребительского поведения. Для реализации поставленной цели могут потребоваться скоординированные действия коллективов потребителей и изменение ориентации программ маркетинга со стороны поставщиков и производителей товаров, которые относятся к категории «зеленых».

Нельзя недооценивать роль и участие государственного сектора, который должен оказывать меры, направленные на поддержку концепции посредством разработки и внедрения регуляционных, структурных и экономических инструментов.

Продвижение принципов концепции «зеленого» потребления должно осуществляться параллельно с конкретными изменениями в образе жизни, экономических действиях и целенаправленной выстроенной политике, которые в совокупности приведут к системным культурным изменениям.

Исследование осуществлено при поддержке Проекта специального фонда Хэйхэского университета 2019 г., направленного на основные научно-исследовательские расходы вузов провинции Хэйлунцзян: «Исследование по потребительской концепции студентов с точки зрения явления онлайн-займов» (номер проекта:2019KYYWF-0469)

\section{ЛИТЕРАТУРА}

1. Garner R. Environmental politics. Britain, Europe and the global environment // Contemporary Political Studies (2nd edn). — L.: MacMillan Press Ltd., 2000.

2. Laroche M., Bergeron J., Barbaro-Forleo G. Targeting consumers who are willing to pay more for environmentally friendly products // Journal of Consumer Marketing. 2001. Vol. 18. № 6. - P. $503-520$.

3. Fraj E, Martinez E. Influence of personality on ecological consumer behavior // Journal of Consumer Behaviour. 2006. Vol. 5. № 6. — P. 167 - 181.

4. Bamberg S., Möser G. Twenty years after Hines, Hungerford and Tomera: A new metaanalysis of psychosocial determinants of proenvironmental behavior // Journal of Environmental Psychology. 2006. Vol. 27. № 1. - P. $14-25$.

5. Stern P.C. New environmental theories: toward a coherent theory of environmentally significant behavior // Journal of Social Issues. 2000. Vol. 56. № 3. — P. 407 - 424.

6. Bhate S. One world, one environment, one vision: Are we close to achieving this? An exploratory study of consumer environmental behavior across three countries // Journal of Consumer Behaviour. 2002. Vol. 2. № 2. - P. $169-184$.

7. Thogersen J. How may consumer policy empower consumers for sustainable lifestyles? // Journal of Consumer Policy. 2005. Vol. 28. № 2. — P. 143 - 177.

8. Wagner-Tsukamoto S., Tadajewski M. Cognitive anthropology and the problem-solving behavior of green consumers // Journal of Consumer Behaviour. 2006. Vol. 5. №3. - P. $235-244$.

9. Gronhoj A. Communication about consumption: A family process perspective on green consumer practices // Journal of Consumer Behaviour. 2006. Vol. 5. № 6. P. $491-503$.

10. Moisander J. Motivational complexity of green consumerism // International Journal of Consumer Studies. 2007. Vol. 30. № 4. — P. 404 - 409.

11. Peattie K., Crane A. Green marketing: Legend, myth, farce or prophesy? // Qualitative Market Research: An Interdisciplinary Journal. 2005. Vol. 8. № 4. — P. 357 - 370.

( Лю Чжэньтао (714913879@qq.com), Бай Юньтао, Сюй Бин. 